\title{
Social Networking Addiction Among Hong Kong University Students: Its Health Consequences and Relationships With Parenting Behaviors
}

\author{
Lu Yu ${ }^{1 *}$ and Tingyu Luo ${ }^{2}$ \\ ${ }^{1}$ Department of Applied Social Sciences, The Hong Kong Polytechnic University, Hong Kong, Hong Kong, ${ }^{2}$ Department of \\ Social Work and Social Administration, The University of Hong Kong, Hong Kong, Hong Kong
}

\section{OPEN ACCESS}

Edited by: Georgios D. Floros, Aristotle University of Thessaloniki, Greece

Reviewed by: loanna Mylona, Aristotle University of Thessaloniki, Greece Lucia Monacis,

University of Foggia, Italy Maria Sinatra

University of Bari Aldo Moro, Italy

${ }^{*}$ Correspondence:

LuYu

lu.yu@polyu.edu.hk

Specialty section: This article was submitted to

Public Mental Health,

a section of the journal

Frontiers in Public Health

Received: 27 April 2020 Accepted: 30 December 2020 Published: 25 January 2021

Citation:

Yu L and Luo T (2021) Social Networking Addiction Among Hong Kong University Students: Its

Health Consequences and

Relationships With Parenting

Behaviors.

Front. Public Health 8:555990. doi: 10.3389/fpubh.2020.555990
The use of social networking sites (SNSs) has been growing at a staggering rate, especially among university students. The present study investigated the prevalence of social networking addiction (SNA), its health consequences, and its relationships with parents' Internet-specific parenting behaviors in a sample of Hong Kong university students $(N=390)$. Adopting the 9-item social media disorder scale, $21.5 \%$ of the participating students met the criteria for SNA. Students with SNA showed longer sleeping latency, more sleep disturbance, poorer academic performance, lower levels of life satisfaction, and higher levels of depression than did students without SNA. Parental reactive restriction and limiting online behaviors of the participants were associated with higher risk of SNA. The findings suggest the severity of SNA and its negative consequences among Hong Kong university students. While parental behaviors limiting children's use of SNSs were found to increase the occurrence rate of SNA among university students, longitudinal studies are needed to further examine this causal relationship.

Keywords: social networking addiction, social networking site, parenting, well-being, university students, Hong Kong

\section{INTRODUCTION}

Social networking sites (SNSs) are defined as web-based services that allow users to "(1) construct a public or semi-public profile within a bounded system, (2) articulate a list of other users with whom they share a connection, and (3) view and traverse their list of connections and those made by others within the system." (p. 211) (1). Through SNSs, people can easily communicate and interact with their friends, family, and people from all over the world on the Web. Facebook, Twitter, and Instagram are among the most popular SNSs while new platforms/websites continue to pop up regularly. A recent report showed that in 2019, there were 3.48 billion SNSs users worldwide (almost half of the Earth's entire population), of which $27 \%$ were young adults aged between 18 and 24 years old (2). Internet users also reported that approximately $27 \%$ of the time spent online was for social media interaction, more than for email, news, and any form of entertainment combined (3). Using SNSs has become not only the most popular online activity but an important part of our daily lives (4). 
While SNSs have brought us enormous convenience and enjoyment, researchers have observed a compulsive tendency among a proportion of SNSs users (5-7). These users feel compelled to use SNSs more excessively to maintain their online social networks, and they also tend to show symptoms that are traditionally associated with substance or other behavioral addiction, such as salience, withdrawal, relapse, growing tolerance, and mood modification (8). This phenomenon has been termed social networking addiction (SNA) or social media addiction, defined as the status of "being overly concerned about SNSs, driven by a strong motivation to log on to or use SNSs, and to devote so much time and effort to SNSs that it impairs other social activities, studies/job, interpersonal relationships, and/or psychological health and well-being" (p. 4,054) (9).

Although SNA has not been formally recognized as a diagnosis, empirical findings across the world generally show that the overall prevalence of SNA is not low. For example, based on a systematic review, Andreassen (10) reported that the prevalence rates of SNA ranged between $1.6 \%$ (in a Nigerian sample) and $34 \%$ (in a Chinese student sample). Growing evidence suggests that SNA is associated with various adverse consequences, such as: poor sleep quality (11), reduced academic and work performance (12), relationship problems (13), impaired selfesteem and life satisfaction (14), and mental health problems $(15,16)$. Researchers have also found brain anatomy alterations associated with SNA, including reduced gray matter volumes in the amygdala bilaterally (17), that are similar to those associated with other forms of behavioral addiction (e.g., gambling).

It is worth noting that university students may be particularly vulnerable to SNA for several reasons. First, university students have notably high Internet literacy which enables them to be the predominant users of SNSs $(18,19)$. Second, compared with secondary school students, university students' online activities are less supervised by their teachers and parents. Third, university students typically have flexible schedules and more free and unlimited access to SNSs. Fourth, developmental characteristics associated with youth may also increase the attraction of SNSs for university students. SNSs use offers young adults new and convenient opportunities to interact with different people, build up intimate relationships, and further develop their identities (20). In fact, ample evidence has been published on the high prevalence of SNA among university students. For instance, using an adapted 6-item Bergen Facebook Addiction Scale (BFAS) (8), Tang and Koh (21) surveyed 1,100 Singapore college students and found that $29.5 \%$ of the respondents could be categorized as having SNA. Another study in China based on Young's Internet addiction criteria revealed an SNA prevalence of 34\% among Chinese college students. In a recent review, it was further revealed that greater exposure to online social networks was associated with greater alcohol use and other addictive behaviors among college students (22). This suggests that SNA in university students has become an important public health issue which deserves more attention from both researchers and the public (4).

Hong Kong is among one of the areas with the highest social media penetration rate in the world. According to the Census and Statistics Department of the Hong Kong Government (23), $75 \%$ of the population are active SNS users, with young adults constituting the majority. It is estimated that the number of young SNS users will continue to grow as more attractive SNS applications and platforms become available. However, direct evidence regarding the prevalence of SNA among Hong Kong university students is limited. Existing studies have either focused on the generalized form of Internet/mobile phone addiction $(24,25)$, or only examined the use of a specific SNS such as Facebook (26). Addictive use of other popular SNSs (e.g., WhatsApp, WeChat, and Twitter) have not been considered, which may mean that the reported prevalence of SNA is an underestimate. Moreover, the consequences of SNA on different domains of quality of life (i.e., physical, mental, and academic) have not been systematically evaluated. Therefore, much remains unknown about how severe SNA is among Hong Kong university students and its impact on students' well-being.

To prevent SNA in university students, it is important to identify the risk and protective factors in the development of SNA. Past research has revealed that specific personality traits (e.g., narcissism, neuroticism), psychological characteristics (e.g., self-esteem), and social factors (e.g., peer influence, loneliness) contribute to the formation of SNA $(27,28)$. However, the role of family in the development of SNA among university students has received little attention, although the impact of parenting behaviors on adolescents' Internet addiction has been reported widely (29-31). For example, neglecting parenting style, inconsistencies, and contradictions between parents (32), family conflicts (33), and parents' psychological control (34) have been found to be associated with increased risk of developing Internet addiction. Parental warmth and acceptance (35), behavioral control $(36,37)$, and good parent-child relationship (38) had negative associations with Internet addiction. Apart from the effects of general parenting style and family functioning, studies have reported on the role of Internet-specific parenting practices, referred to as parenting behaviors that specifically aim to guide their children's use of the Internet and minimize its negative consequences (39), in protecting youth from Internet addiction (33, 40). For instance, Chng et al. (41) found that parental restrictive mediation (i.e., parents' restriction of their children's Internet use) was negatively related to adolescents' Internet addiction based on a sample of Singapore secondary school students. In van den Eijnden et al.'s (39) study, parental active mediation, defined as interaction and communication regarding online activities between children and parents, predicted decreased pathological Internet use. Nevertheless, few studies investigating how parenting behaviors may influence university students' addictive behaviors including SNA have been published.

This lack of research could be explained by the fact that the increased autonomy of university students results in their declined reliance on family in their development (42). They attempt to separate their lives from the control of their parents to develop independence and take responsibility of their own world (43). Thus, the effects of parenting behaviors are considered as collectively less important than those of other factors, such as peers and personal attributes. Nonetheless, a few studies suggest that parents continue to exert direct and indirect effects on young adults' lives, whether in the psychological or social domain. For instance, researchers have reported significant 
relationships between university students' substance use and their parents' behavioral control, family communication, and parent-child relationship (44-48). Parental rejection and paternal overprotection have been found to be positively associated with Chinese university students' risks of Internet addiction (49).

In the context of Hong Kong, the influence of parents on university students may be more profound for several reasons. First, due to the limited residential places offered by universities and high housing expenses, most Hong Kong local students remain living with their family members after entering university (50). This potentially makes the influence of parenting behaviors greater on university students in Hong Kong than in other countries and areas. Second, parental influence on young people's behaviors may also be strengthened by Chinese cultural values, which emphasize parental authority and children's obedience (51). Third, although Chinese parents are likely to be more restrictive than Western parents (52), Chinese children tend to consider their parents' behavioral monitoring as a sign of parental warmth and responsiveness (53-55). Thus, it is possible that Hong Kong university students may be more receptive to their parents' mediation regarding their Internet use than people in cultures where autonomy is more emphasized. Based on these socio-cultural characteristics, it seems reasonable to assume that parents of Hong Kong university students may still play an influencing role in their development of SNA.

\section{The Present Study}

Considering the background explained above, the present study had three purposes. First, we aimed to preliminarily examine the prevalence of SNA based on a sample of Hong Kong university students. Second, we sought to investigate the association between SNA and a variety of health outcomes, including sleep quality, depression, life satisfaction, and academic performance among Hong Kong university students. Third, we intended to address the predictive effects of parenting behaviors on university students' SNA. In particular, we focused on Internet-specific parenting practices based on the parental mediation theory (56). According to this theory, three types of parenting practices are related to youth compulsive SNS use: active mediation (i.e., parent-adolescent conversations regarding online activities), restrictive mediation (i.e., allowance to use particular online applications), and social co-use (i.e., children using the Internet in the company of their parents, such as watching movies online and playing Internet games together). Apart from parental mediation, parents' own use of SNSs is regarded as another factor that influences their children's behaviors through social modeling. Previous studies have supported the protective effect of these parenting practices on adolescents' problematic use of computers, electronic devices, and the Internet $(39,57)$. In the present study, the respective effects of the three types of parenting behaviors on university students' SNA were investigated.

\section{METHODS}

\section{Participants and Procedure}

The present study was carried out with undergraduate students in a public university in Hong Kong. In 2018/19 academic year, students taking a selective introductory psychology course offered to all undergraduate students in the university were recruited on a voluntary basis. An invitation letter containing a brief introduction about the study and a consent form was emailed to all students enrolled in this subject $(N=490$ including 217 male students and 273 female students). Students who agreed to participate were required to return their signed consent forms, after which they were provided with a link to an online questionnaire. They completed the survey anonymously within the first month of the semester. Ethical approval of the study was obtained from the Human Subjects Ethics Committee of the first authors' institution. All data collected in the study were kept strictly confidential and analyzed in an aggregated manner.

The final sample of participants totaled 390 students (Mean age $=19.09$ years, $\mathrm{SD}=1.47)$ consisted of $176(45.13 \%)$ males and $214(54.87 \%)$ females, indicating an overall response rate of $79.6 \%$. The students were from eight different faculties and schools of the university, with the majority from the School of Business ( $n=246,63.07 \%)$ followed by students in the Faculty of Health and Social Sciences $(n=54,13.85 \%)$. Regarding year of study, $68.5 \%$ of the participants $(n=267)$ were in their first year of university, $18.7 \%(n=73)$ were in their second year, $6.4 \%(n$ $=25)$ were in their third year, $5.6 \%(n=22)$ were in their fourth year, and $0.8 \%(n=3)$ were in their fifth year.

\section{Measures}

To measure participants' SNS usage behaviors, SNA, mental health status, and their parents' Internet-specific parenting behaviors, five core scales were used, which are described below. Cronbach's alpha of each scale for the present sample is presented in Table 1. Apart from these scales, students responded to a few items asking about their demographic information and academic performance in the latest semester. Specifically, we asked students to report their perceived academic performance, comparing to other students of the same cohort, in the last semester, based on a five-point rating scale ( $1=$ very poor, $2=$ poorer than others, 3 $=$ average, $4=$ better than others, and $5=$ very good).

\section{Social Media Disorder Scale (SMD)}

In the present study, we adopted the 9-item Social Media Disorder Scale (58) to assess participants' SNA. The SMD was developed using similar diagnostic criteria to that of Internet Gaming Disorder (DSM-V). Each item measures a unique dimension of SNA, including preoccupation, tolerance, withdrawal, persistence, escape, problems, deception, displacement, and conflict. Respondents answer "Yes" or "No" regarding whether they have had the listed SNA behavior in the past 1 year. Example items include "often used social media to escape from negative feelings," and "tried to spend less time on social media, but failed." A person is classified as having SNA if he or she shows five or more of the listed behaviors. Previous studies have demonstrated the robust psychometric properties of the 9-item $\operatorname{SMD}(59,60)$. Cronbach's alpha of this scale for the current sample was 0.72 . 
TABLE 1 | Descriptive statistics of the key variables.

\begin{tabular}{|c|c|c|c|c|c|c|c|c|}
\hline \multirow[t]{2}{*}{ Continuous variables } & \multicolumn{3}{|c|}{ Total $(N=390)$} & \multicolumn{2}{|c|}{ Male $(N=176)$} & \multicolumn{2}{|c|}{ Female $(N=214)$} & \multirow[b]{2}{*}{$t$} \\
\hline & Cronbach's alpha & Mean & SD & Mean & SD & Mean & SD & \\
\hline Age & - & 19.09 & 1.47 & 19.11 & 1.79 & 19.04 & 1.14 & 0.45 \\
\hline Life satisfaction & 0.86 & 4.10 & 1.16 & 4.03 & 1.14 & 4.16 & 1.18 & 1.15 \\
\hline Depression & 0.87 & 1.95 & 0.54 & 1.98 & 0.51 & 1.93 & 0.57 & -0.90 \\
\hline Sleep disturbance & 0.81 & 0.65 & 0.54 & 0.71 & 0.53 & 0.61 & 0.54 & -1.88 \\
\hline Sleep latency & - & 1.29 & 1.05 & 1.40 & 1.06 & 1.20 & 1.04 & -1.84 \\
\hline Perceived academic performance & - & 3.00 & 0.75 & 2.91 & 0.83 & 3.07 & 0.67 & 2.12 \\
\hline \multicolumn{9}{|l|}{ Specific parenting behaviors } \\
\hline Reactive restriction & 0.88 & 1.71 & 0.82 & 1.90 & 0.89 & 1.54 & 0.72 & $-4.32^{\star \star \star}$ \\
\hline Internet-specific rules & 0.92 & 3.24 & 0.99 & 3.22 & 0.97 & 3.25 & 1.01 & 0.39 \\
\hline Limiting online behavior & 0.77 & 1.97 & 0.77 & 2.10 & 0.80 & 1.86 & 0.73 & $-3.09^{\star \star}$ \\
\hline Communication about the internet & 0.74 & 3.09 & 0.92 & 3.01 & 0.90 & 3.16 & 0.93 & 1.55 \\
\hline Co-use & 0.84 & 2.25 & 0.89 & 2.17 & 0.86 & 2.31 & 0.92 & 1.55 \\
\hline Parent-adherence & 0.82 & 2.47 & 0.82 & 2.54 & 0.83 & 2.41 & 0.81 & -1.54 \\
\hline SNA & 0.72 & 2.80 & 2.21 & 2.96 & 2.36 & 2.66 & 2.08 & -1.30 \\
\hline
\end{tabular}

${ }^{* *} p<0.01 ;{ }^{* * *} p<0.001$

\section{Satisfaction With Life Scale (SWLS)}

Life Satisfaction was assessed using the 5-item Satisfaction with Life Scale (61), a well-known self-reported scale. Each item is rated on a 7-point Likert scale ranging from 1 (strongly disagree) to 5 (strongly agree). A higher score represents a higher level of life satisfaction. The SWLS has shown good psychometric properties in different cultural contexts with different populations $(14,62,63)$. In the present study, the scale had a high Cronbach's alpha of 0.86 .

\section{Patient Health Questionnaire (PHQ-9)}

Depression was measured using the 9-item Patient Health Questionnaire (64), a self-report tool developed to assess mental disorder using DSM-IV criteria. The PHQ-9 has been translated into various languages and evaluated in different ethnic groups and countries, including China $(65,66)$. Participants rated each item based on a 4 -point Likert scale $(0=$ not at all; $3=$ nearly every day). A higher score represents a higher level of depression. The Cronbach's alpha for the current sample was 0.87 .

\section{Internet-Specific Parenting Behaviors Scale}

Internet-specific parenting behaviors were assessed using Koning et al.'s (57) scale adapted from an earlier version measuring parenting behaviors related to Internet use developed by van Den Eijnden et al. (39). The adapted scale asks participants to report the frequency of certain behaviors displayed by their parents when they want to be online (i.e., everything they do on the Internet with a smartphone, tablet, or computer) or gaming, including six subscales that measure three major types of parental mediation (restrictive mediation, active mediation, and social co-use) and parents' own use of SNSs. "Reactive restriction" (4 items) reflects parents' restrictive responses to their children's use of SNSs or gaming (e.g., "how often do your parents say that you can't be on social media or gaming?'). "Internet-specific rules" ( 9 items) measures the extent to which parents set strict rules on when and how long their children can use the Internet. The subscale of "limiting online behaviors" (4 items) assesses parents' controlling behaviors that stop children from using the Internet (e.g., taking away phones or tablets, turning off Wi-Fi, and commanding angrily). These three subscales reflect parents' restrictive mediation. "Quality of communication" (3 items) asks participants about their feelings when their parents talk with them about their online activities, which reflects parents' active mediation. The other two subscales, "co-use" (3 items) and "parent adherence" (4 items), measure the extent to which parents monitor their children's Internet use or remain present while their children are using social media (social couse), and parents' own use habits at home, respectively. These two subscales show parental modeling and co-using behaviors. Participants responded to each item on a 5-point rating scale, with higher scores representing higher frequency of the measured behaviors. The internal consistencies of the six subscales were all above 0.74 in the present study.

\section{Pittsburgh Sleep Quality Index (PSQI)}

Participants' sleep quality was measured by nine items excerpted from the Pittsburgh Sleep Quality Index (67). The PSQI is a validated questionnaire that assesses one's quality of sleep and sleep disturbances in the last month $(68,69)$. Sleep latency was measured by the item "during the past month, how often have you had trouble sleeping because you cannot get to sleep within 30 min." Sleep disturbance was measured by eight items on different problems that can disturb one's sleep, such as "wake up in the middle of the night or early morning," and "have to get up to use the bathroom." Participants rated each item on a 4point scale from 0 to 3 ( $0=$ not during the past month; $1=$ less than once a week; $2=$ once or twice a week; $3=$ three or more times a week). In this study, Cronbach's alpha for the eight sleep disturbance items was 0.81 . 


\section{Statistical Analysis}

First, descriptive statistics on participants' problematic use of SNSs and prevalence of SNA were calculated for the whole sample, and for students of different gender, respectively. Independent samples $t$-tests were performed to examine whether males and females differed in the key variables. Bivariate correlation analyses were also conducted to test the preliminary associations between SNA, health indicators, and Internetspecific parenting behaviors. Second, independent-samples $t$ tests were conducted to compare students with and without SNA in terms of their life satisfaction, depression, sleep latency and disturbance, and perceived academic performance. Third, logistic regression was conducted to examine the extent to which different Internet-specific parenting behaviors would predict university students' SNA based on the whole sample, and on samples of males and females, respectively.

\section{Ethics}

The study procedures were carried out in accordance with the guidelines of the Declaration of Helsinki. The data collection received ethical approval from the Human Subjects Ethics Subcommittee of the first author's university. All subjects were informed about the study and all of them signed consent forms before the survey.

\section{RESULTS}

Descriptive statistics of all variables in this study were first calculated and summarized. Table 1 presents the means and standard deviations of all continuous variables (e.g., age, life satisfaction, and depression). For parents' reactive restriction $(t$ $=-4.32, p<0.001)$ and limiting online behavior $(t=-3.09$, $p<0.01$ ), male students scored significantly higher than female students. All other variables did not show significant gender difference. Table 2 summarizes simple correlation coefficients among SNA, health indicators, and Internet-specific parenting behaviors. Based on the whole sample, the correlations between health indicators and SNA were all significant ( $p s$ $<0.05)$. High SNA was associated with longer sleep latency, more sleep disturbance, higher level of depression, lower life satisfaction, and lower perceived academic performance. On the other hand, Internet-specific parenting behaviors including reactive restriction, limiting online behavior, co-use, and parent adherence were positively related to participants' reported SNA. Similar findings were observed in the male sample and the female sample, respectively. For both males and females, SNA was positively related to depression and sleep latency; SNA was also found to be positively associated with parents' reactive restriction, limiting online behavior, and parents' co-use.

\section{Prevalence of Social Networking Addiction}

Table 3 presents the numbers and percentages of participants who displayed different SNA behaviors in the past year measured by the Social Media Disorder Scale. Nearly half (49.5\%) of the participants reported that they often used social media to escape from negative feelings. More than $40 \%$ reported that they were preoccupied by social media usage $(44.1 \%)$, tried to spend less time on social media but failed (44.9\%), and often felt bad when they could not use social media (40.0\%). These results show that addictive behaviors associated with SNS use are quite common among Hong Kong university students. While relatively fewer participants reported interpersonal problems caused by their social media use (16.2\% had arguments with others and $15.4 \%$ had serious conflicts with family members), more than onefifth of the participants said that they regularly neglected other activities because they wanted to use social media. Adopting the criteria used by Van den Eijnden et al. (59), 84 participants could be classified as having SNA, indicating an overall prevalence rate of $21.5 \%$ among the current sample of university students. Among the 84 identified students, 44 were males and 40 were females; while the prevalence of SNA appeared to be higher among male students (25.0\%) than female students (18.7\%), the difference did not reach statistical significance $\left(X^{2}=2.27\right.$, $p=0.13)$.

\section{Health Consequences of Social Networking Addiction}

Results of the independent samples $t$-tests based on bootstrapping (Table 4) show that participants who met the criteria of SNA displayed longer sleep latency, more sleep disturbance, lower life satisfaction, and higher levels of depression compared to those in the non-SNA group. Students with SNA also reported lower levels of perceived academic performance than did those without SNA. All differences are statistically significant $(p s<0.05)$. Students who displayed more SNA behaviors tended to have poorer health status in multiple areas.

\section{Predictive Effects of Internet-Specific Parenting Behaviors on Social Networking Addiction}

Table 5 reports the results of the logistic regression analysis. First, students' year of study and gender failed to predict the occurrence of SNA. Second, two specific parenting behaviors, reactive restriction $(\mathrm{OR}=1.78 ; 95 \% \mathrm{CI}=1.24-2.55)$ and limiting online behaviors $(\mathrm{OR}=1.72 ; 95 \% \mathrm{CI}=1.11-2.65)$, were found to be associated with higher probability of students being classified as having SNA. The other four parenting behaviors, including setting strict rules on Internet use, quality of communication, couse, and parent adherence, all failed to predict the occurrence of SNA. Another two logistic regression analyses were performed on the male sample and the female sample, respectively. Consistent with findings generated from the whole sample, parents' limiting online behaviors were positively associated with higher probability of male students being classified as having SNA $(\mathrm{OR}=2.13 ; 95 \% \mathrm{CI}=1.11-4.09)$; parents' reactive restriction was positively associated with female students' risk for SNA $(\mathrm{OR}=2.44 ; 95 \% \mathrm{CI}=1.40-4.25)$.

\section{DISCUSSION}

The present study investigated the prevalence of SNA, its health consequences, and its relationships with Internet-specific 
TABLE 2 | Correlations between social networking addiction, health indicators, and internet-specific parenting behaviors.

\begin{tabular}{|c|c|c|c|c|c|c|c|c|c|c|c|}
\hline The whole sample ${ }^{a}$ & SNA & LS & Depression & SLD & SLL & $\mathbf{R R}$ & IR & LB & QC & $\mathrm{CU}$ & PA \\
\hline SNA & - & & & & & & & & & & \\
\hline LS & $-0.10^{\star}$ & - & & & & & & & & & \\
\hline SLD & $0.32^{\star \star}$ & $-0.15^{\star \star}$ & $0.56^{\star \star}$ & - & & & & & & & \\
\hline SLL & $0.15^{\star \star}$ & -0.06 & $0.27^{\star \star}$ & $0.34^{\star \star}$ & - & & & & & & \\
\hline LB & $0.31^{\star \star}$ & 0.02 & $0.29^{\star \star}$ & $0.21^{\star \star}$ & 0.00 & $0.58^{\star \star}$ & $-0.25^{\star \star}$ & - & & & \\
\hline QC & -0.06 & $0.13^{*}$ & -0.06 & -0.04 & -0.07 & $-0.15^{\star \star}$ & $0.19^{\star \star}$ & 0.01 & - & & \\
\hline $\mathrm{CU}$ & $0.16^{\star \star}$ & $0.12^{*}$ & $0.14^{\star \star}$ & $0.17^{\star \star}$ & -0.03 & $0.19^{\star \star}$ & 0.02 & $0.36^{\star \star}$ & $0.17^{\star \star}$ & - & \\
\hline PA & $0.11^{\star}$ & 0.03 & $0.15^{\star \star}$ & $0.18^{\star \star}$ & 0.00 & $0.18^{\star \star}$ & $0.18^{\star \star}$ & $0.25^{\star \star}$ & 0.01 & $0.30^{\star *}$ & - \\
\hline By gender ${ }^{b}$ & SNA & LS & Depression & SLD & SLL & $\mathrm{RR}$ & $\mathbb{R}$ & LB & QC & $\mathrm{CU}$ & PA \\
\hline SLL & 0.13 & -0.04 & $0.21^{\star \star}$ & $0.29^{\star \star}$ & - & 0.03 & 0.13 & -0.05 & -0.02 & -0.01 & -0.08 \\
\hline $\mathrm{RR}$ & $0.30^{\star \star}$ & 0.02 & $0.27^{\star \star}$ & $0.36^{\star \star}$ & 0.01 & - & $-0.18^{\star \star}$ & $0.52^{\star \star}$ & -0.09 & $0.22^{\star *}$ & 0.08 \\
\hline $\mathbb{R}$ & -0.11 & -0.05 & 0.11 & 0.04 & 0.06 & $-0.30^{\star \star}$ & - & $-0.15^{\star}$ & $0.17^{\star}$ & 0.09 & $0.20^{\star *}$ \\
\hline LB & $0.35^{\star \star}$ & 0.03 & $0.29^{\star \star}$ & $0.26^{\star \star}$ & 0.02 & $0.61^{\star \star}$ & $-0.36^{\star \star}$ & - & 0.08 & $0.37^{\star *}$ & $0.18^{* *}$ \\
\hline QC & -0.09 & 0.11 & -0.03 & -0.10 & -0.11 & $-0.17^{\star}$ & $0.20^{\star \star}$ & -0.06 & - & $0.23^{\star *}$ & 0.04 \\
\hline $\mathrm{CU}$ & $0.21^{\star \star}$ & 0.01 & 0.13 & $0.18^{*}$ & -0.03 & $0.21^{\star \star}$ & -0.08 & $0.39^{\star \star}$ & 0.09 & - & $0.23^{\star \star}$ \\
\hline PA & $0.22^{\star \star}$ & -0.02 & $0.30^{\star \star}$ & $0.28^{\star \star}$ & 0.08 & $0.25^{\star \star}$ & $0.16^{\star}$ & $0.32^{\star \star}$ & -0.01 & $0.42^{\star *}$ & - \\
\hline
\end{tabular}

LS, life satisfaction; SLD, sleep disturbance; SLL, sleep latency; RR, reactive restriction; IR, internet-specific rules; $L B$, limiting online behaviors; $Q C$, quality of communication; CU, co-use; PA, parent adherence.

a Pearson correlation coefficients calculated based on the whole sample $(N=390)$.

${ }^{b}$ Pearson correlation coefficients calculated for males $(N=176)$ and females $(N=214)$, respectively; values below the diagonal are for males; values above the diagonal are for females. $" p<0.05 ; * p<0.01$.

TABLE 3 | Prevalence of social networking addiction behaviors.

\begin{tabular}{lcc}
\hline During the past year, have you... & Yes \\
\cline { 2 - 2 } & Number & Percentage (\%) \\
\hline 1. Regularly found that you can't think of anything else but the moment that you will be able to use the social media again? & 172 \\
2. Regularly felt dissatisfied because you wanted to spend more time on social media? & 118 \\
3. Often felt bad when you could not use social media? & 156 \\
4. Tried to spend less time on social media, but failed? & 175 \\
5. Often used social media to escape from negative feelings? & 193 \\
6. Regularly had arguments with others because of your social media use? & 63 \\
7. Regularly lied to your parents or friends about the amount of time you spend on social media? & 40.3 \\
8. Regularly neglected other activities (e.g., hobbies, sport) because you wanted to use social media? & 40.9 \\
9. Had serious conflicts with your parent(s) and/or sibling(s) because of your social media use? & 16.2 \\
Social networking addiction (yes on five or more items) & 17.9 \\
\end{tabular}

parenting behaviors in a group of Hong Kong university students. More than one-fifth of the participants could be regarded as at high risk of SNA, which was further found to be associated with multiple negative health consequences including poor sleeping quality, mental well-being, and academic performance. This suggests that SNA has become a serious public health issue affecting the lives of a considerable number of young adults.
Effective intervention and prevention strategies are critically needed to tackle the problem in a timely manner. Meanwhile, parental reactive restriction and limiting online behavior were associated with higher probability of university students' SNA.

We found an overall SNA prevalence of $21.5 \%$ among the surveyed Hong Kong university students, which is consistent with previous findings showing that $12-34 \%$ of young adults 
TABLE 4 | Independent samples t-tests comparing health indicators between SNA and non-SNA groups based on 1,000 bootstrap samples.

\begin{tabular}{|c|c|c|c|c|}
\hline Health indicators & Non-SNA group $(N=306)$ & SNA group $(N=84)$ & $t$ & $p$ \\
\hline Sleep latency & $2.23(1.06)$ & $2.52(1.01)$ & -2.31 & 0.02 \\
\hline Sleep disturbance & $1.58(0.47)$ & $1.91(0.66)$ & -4.28 & 0.00 \\
\hline Academic performance & $3.40(0.75)$ & $2.85(0.74)$ & 2.11 & 0.04 \\
\hline Depression & $1.86(0.50)$ & $2.29(0.57)$ & -6.85 & 0.00 \\
\hline Life satisfaction & $4.16(1.16)$ & $3.88(1.18)$ & 2.00 & 0.05 \\
\hline
\end{tabular}

TABLE 5 | Logistic regression analysis of the prediction of SNA by parenting behaviors.

\begin{tabular}{|c|c|c|c|c|c|c|c|c|c|c|c|c|}
\hline \multirow[b]{2}{*}{ Predictors } & \multicolumn{4}{|c|}{ The whole sample } & \multicolumn{4}{|c|}{ Male students } & \multicolumn{4}{|c|}{ Female students } \\
\hline & B & SE & OR & $95 \% \mathrm{Cl}$ & B & SE & OR & $95 \% \mathrm{Cl}$ & B & SE & OR & $95 \% \mathrm{Cl}$ \\
\hline \multicolumn{13}{|l|}{ Block 1} \\
\hline Gender & -0.37 & 0.25 & 0.70 & $0.43-1.13$ & - & - & - & - & - & - & - & - \\
\hline Year of study & 0.03 & 0.14 & 1.03 & $0.79-1.34$ & -0.07 & 0.19 & 0.94 & $0.65-1.35$ & 0.14 & 0.20 & 1.15 & $0.78-1.69$ \\
\hline \multicolumn{13}{|l|}{ Block 2} \\
\hline Reactive restriction & 0.57 & 0.19 & $1.78^{\star \star}$ & $1.24-2.55$ & 0.28 & 0.25 & 1.33 & $0.81-2.18$ & 0.89 & 0.28 & $2.44^{\star \star}$ & $1.40-4.25$ \\
\hline Internet-specific rules & 0.11 & 0.16 & 1.11 & $0.81-1.53$ & 0.08 & 0.26 & 1.08 & $0.65-1.80$ & 0.16 & 0.22 & 1.17 & $0.77-1.79$ \\
\hline Limiting online behaviors & 0.54 & 0.22 & $1.72^{\star}$ & $1.11-2.65$ & 0.76 & 0.33 & $2.13^{*}$ & $1.11-4.09$ & 0.35 & 0.31 & 1.42 & $0.77-2.62$ \\
\hline Quality of communication & -0.17 & 0.16 & 0.85 & $0.62-1.17$ & -0.25 & 0.25 & 0.78 & $0.47-1.28$ & -0.09 & 0.22 & 0.91 & $0.60-1.39$ \\
\hline Co-use & 0.23 & 0.17 & 1.26 & $0.90-1.75$ & 0.22 & 0.26 & 1.24 & $0.75-2.07$ & 0.16 & 0.23 & 1.18 & $0.75-1.84$ \\
\hline Parental adherence to rules & -0.01 & 0.19 & 0.99 & $0.69-1.43$ & 0.29 & 0.28 & 1.33 & $0.78-2.29$ & -0.29 & 0.27 & 0.75 & $0.44-1.27$ \\
\hline Cox and Snell $R^{2}$ & \multicolumn{4}{|c|}{0.12} & 0.15 & \multicolumn{7}{|c|}{0.11} \\
\hline
\end{tabular}

${ }^{*} p<0.05 ;{ }^{* \star} p<0.01$.

are problematic users of SNSs worldwide $(10,70)$. Nonetheless, while some evidence suggests that SNA appears to be more prevalent among females (27), the present study found SNA to be unrelated to university students' gender. A recent report based on college students in Singapore showed similar findings (21). It should be noted that despite the nonsignificant gender difference in prevalence, males and females may use SNSs for distinct purposes and display different online behaviors associated with SNS usage (71). For example, Muscanell and Guadagno (72) reported that men tended to use SNSs for forming new relationships while women were more likely to use SNSs for relationship maintenance. Females also reported using SNSs more broadly than did males (73). Further investigation into gender-specific motivations and SNS usage behaviors would help inform the development of prevention and intervention programs targeting different gender groups.

It is worth noting that the most frequently reported SNA behaviors in the present study are related to "mood modification," "salience," and "withdrawal symptoms." More than $40 \%$ of the participating students indicated that they used SNSs to escape from negative feelings, felt bad when they could not use SNSs, and tried to spend less time on SNSs but failed. These behaviors resemble some core symptoms of other types of behavioral addiction like gambling and gaming disorder (74). Such problematic behavioral patterns often lead to further emotional, performance-related, and health problems in one's life.
In fact, we found that students with SNA in the present study reported poorer sleeping quality (longer sleep latency and more sleep disturbance), lower levels of life satisfaction and perceived academic performance, and higher levels of depression. These findings provide further evidence for the pervasive negative impact of SNA on the health and well-being of university students in the context of Hong Kong. Corroborating with prior reports based on other populations (75-77), the present study suggests that despite of the positive benefits and impacts of SNS, there is a significant detrimental effect on many aspects of life including academic achievement among people who cannot control their excessive uses of SNS, especially youth who are still in education. Recent studies showed that cognitive reconstruction about SNSs use could effectively mitigate SNA by helping students realize the adverse effects of SNA and the potential benefits of reducing SNS usage (78). The present findings can be used in the development of such psychoeducational programs to prevent and treat SNA among university students in Hong Kong. Besides, intervention programs targeting SNA shall not only focus on reducing one's SNS use, but develop strategies to improve the health and wellbeing status of the addictive users, such as addressing their depression and sleeping problems, and providing support to improve their learning efficiency and academic performance.

Regarding the influence of parental Internet-specific behaviors, the present study revealed a positive relationship between parental restrictive mediation (i.e., reactive restriction and limiting online behaviors) and university students' SNA. In 
other words, more controlling behaviors displayed by parents regarding their children's use of SNSs (e.g., asking their children to turn off their mobile phones) are associated with a higher risk of SNA among university students. This counterintuitive finding may actually reflect a reverse causality, i.e., parents simply engage in more restrictive behaviors after observing their children's addictive use of SNSs. Previous studies showed inconsistent findings where parental restrictive mediation was found to be positively $(79,80)$, negatively $(41,81)$, or insignificantly $(82)$ related to their children's addictive use of Internet. Researchers have proposed that the association between parental mediation strategies and their children's behavior may be further moderated by other factors $(37,82-84)$. For example, Lee (82) reported the child's low self-control reinforced the effects of restrictive mediation on the child's online time. Besides, the effects of concrete parenting practices (i.e., Internet-specific parenting behaviors) may also be moderated by general family functioning and parenting style (83). Parent-child relationship and family dynamics have consistently been found to affect the influence of specific parenting practices on children's development and mental health $(85,86)$. In the present study, we did not include indicators of general parenting behaviors (e.g., responsiveness and demandingness) or family climate when investigating the influence of Internet-specific parental behaviors on university students' SNA. Such indicators shall be taken into account in future studies. More importantly, the causal relationship between Internet-specific parenting behavior and children's SNA, as well as the potential moderators must be addressed based on longitudinal research.

Other parenting behaviors including parents' own SNS usage, social co-use, and quality of communication were all found to have no significant relationship with university students' SNA. This is consistent with existing findings showing that the salience of parents' direct influence on adolescents' behaviors recedes as adolescents increasingly incorporate more extra-familial socialization influence into their sense of identity $(87,88)$. Peer modeling and norms have been highlighted as powerful determinants of young people's addictive behaviors such as drinking and digital game addiction $(89,90)$. Besides, although most university students in Hong Kong remain living at home, they spend little time with their parents. A recent survey revealed that $92 \%$ of Hong Kong university students had extra-curricular jobs for further financial support (91), which likely took away from family time. Limited family time may further weaken parental influence on children's behaviors. In addition, similar to parental restrictive mediation, the effects of Internet-specific parenting behaviors (e.g., parents monitoring children's SNS use) are likely to be moderated by one's family relationships and the general parenting styles that parents display over time. We need more in-depth investigation into the role of family dynamics in the association between parenting behaviors and young people's SNA.

Several limitations of the present study must be acknowledged. First, although we found significant relationships between SNA and different health indicators, the direction of the relationships cannot be confirmed based on the crosssectional study. Some scholars $(25,92)$ have reported reciprocal relationships between Internet addiction and one's well-being, indicating the possibility that individuals with more emotional disturbance may be more likely to use SNSs intensively in order to escape from the real world, and the excessive time used on SNSs further causes problems in one's life. This issue must be addressed with multiple waves of data collected in future longitudinal research. Second, parenting behaviors were measured only based on university students' perceptions. Further studies should collect data from multiple informants, for example by using parents' self-reported behaviors. Third, participants in the present study were recruited from a convenient sample. To gain a more accurate estimation of the prevalence rate of SNA among university students in Hong Kong, large-scale studies based on representative samples are necessary.

Despite these limitations, the present study is among the first to examine SNA and its relationships with multiple health outcomes and parenting behaviors among university students in Hong Kong. The findings highlight the severity of the issue. Timely prevention and detection of SNA should be given priority in terms of health education resources for university students. Moreover, as our understanding of parenting behaviors regarding SNS usage continues to develop, researchers in this area might be able to provide a more complete and clear framework of the relationship between SNA and parenting behaviors, as well as the underlying mechanism.

\section{DATA AVAILABILITY STATEMENT}

The raw data supporting the conclusions of this article will be made available by the authors, without undue reservation.

\section{ETHICS STATEMENT}

The studies involving human participants were reviewed and approved by Human Subjects Ethics Sub-committee, Department of Applied Social Sciences, The Hong Kong Polytechnic University. The patients/participants provided their written informed consent to participate in this study.

\section{AUTHOR CONTRIBUTIONS}

LY conceptualized and designed the study, collected the data, interpreted the data, drafted the manuscript, and approved the final manuscript as submitted. TL collected the data, interpreted the data, drafted the manuscript, and approved the final manuscript as submitted. Both authors contributed to the article and approved the submitted version.

\section{FUNDING}

The work described in this manuscript was fully supported by a grant from the Research Grants Council of the Hong Kong Special Administrative Region, China (Project No. PolyU 15604618). 


\section{REFERENCES}

1. Boyd D M, Ellison $\mathrm{N}$ B. Social network sites: definition, history, and scholarship. J Comput Mediat Commun. (2007) 13:210-30. doi: 10.1111/j.1083-6101.2007.00393.x

2. We are social. Digital 2019: Global Internet Use Accelerates [Internet]. Available online at: https://wearesocial.com/blog/2019/01/digital-2019-globalinternet-use-accelerates (cited April 16, 2020).

3. Tatham, M. For Every Hour Online Americans Spend 16 Minutes on Social Networks [Internet]. Available online at: http://www.experian.com/blogs/ marketing-forward/2013/04/18/for-every-hour-online-americans-spend-16minutes-on-social-networks/ (cited April 16, 2020).

4. Kuss DJ, Griffiths MD. Addiction to social networks on the internet: a literature review of empirical research. Int J Environ Publ Health. (2011) 8:3528-52. doi: 10.3390/ijerph8093528

5. Brady KP, Holcomb LB, Smith BV. The use of alternative social networking sites in higher educational settings: a case study of the e-learning benefits of Ning in education. J Inter Online Learn. (2010) 9:151-70. doi: 10.1108/CWIS-11-2013-0062

6. Ellison N B, Steinfield C, Lampe C. The benefits of Facebook "friends:" Social capital and college students' use of online social network sites. J Comput Mediat Commun. (2007) 12:1143-68. doi: 10.1111/j.1083-6101.2007.00367.x

7. Livingstone $S$, Brake DR. On the rapid rise of social networking sites: new findings and policy implications. Child Soc. (2010) 24:7583. doi: 10.1111/j.1099-0860.2009.00243.x

8. Andreassen CS, Torsheim T, Brunborg GS, Pallesen S. Development of a Facebook addiction scale. Psychol Rep. (2012) 110:50117. doi: 10.2466/02.09.18.PR0.110.2.501-517

9. Schou Andreassen C, Pallesen S. Social network site addiction-an overview. Curr Pharm Des. (2014) 20:4053-61. doi: 10.2174/13816128113199990616

10. Andreassen CS. Online social network site addiction: a comprehensive review. Curr Addict Rep. (2015) 2:175-84. doi: 10.1007/s40429-015-0056-9

11. Xanidis N, Brignell CM. The association between the use of social network sites, sleep quality and cognitive function during the day. Comput Human Behav. (2016) 55:121-6. doi: 10.1016/j.chb.2015.09.004

12. Leung L. Using tablet in solitude for stress reduction: An examination of desire for aloneness, leisure boredom, tablet activities, and location of use. Comput Human Behav. (2015) 48:382-91. doi: 10.1016/j.chb.2015.01.068

13. Elphinston RA, Noller P. Time to face it! Facebook intrusion and the implications for romantic jealousy and relationship satisfaction. Cyberpsychol Behav Soc Netw. (2011) 14:631-5. doi: 10.1089/cyber.2010.0318

14. Hawi NS, Samaha M. The relations among social media addiction, selfesteem, and life satisfaction in university students. Soc Sci Comput Rev. (2017) 35:576-86. doi: 10.1177/0894439316660340

15. Pantic I. Online social networking and mental health. Cyberpsychol Behav Soc Netw. (2014) 17:652-7. doi: 10.1089/cyber.2014.0070

16. Cerniglia L, Griffiths MD, Cimino S, De Palo V, Monacis L, Sinatra M, et al. A latent profile approach for the study of internet gaming disorder, social media addiction, and psychopathology in a normative sample of adolescents. Psychol Res Behav Manage. (2019) 12:651-9. doi: 10.2147/PRBM.S211873

17. He Q, Turel O, Bechara A. Brain anatomy alterations associated with Social Networking Site (SNS) addiction. Sci Rep. (2017) 7:1-8. doi: 10.1038/srep45064

18. Griffiths KM, Bennett K, Walker J, Goldsmid S, Bennett A. Effectiveness of $\mathrm{MH}-\mathrm{Guru}$, a brief online mental health program for the workplace: a randomised controlled trial. Internet Interv. (2016) 6:29-39. doi: 10.1016/j.invent.2016.09.004

19. Perrin A. Social Media Usage. Pew Research Center [Internet]. (2015). Available online at: https://www.secretintelligenceservice.org/wp-content/ uploads/2016/02/PI_2015-10-08_Social-Networking-Usage-2005-2015_ FINAL.pdf

20. Griffiths MD. Social networking addiction: emerging themes and issues. $J$ Addict Res Ther. (2013) 4. doi: 10.4172/2155-6105.1000e118

21. Tang CS, Koh YYW. Online social networking addiction among college students in Singapore: comorbidity with behavioral addiction and affective disorder. Asian J Psychiatr. (2017) 25:175-8. doi: 10.1016/j.ajp.2016. 10.027
22. Rinker DV, Krieger H, Neighbors C. Social network factors and addictive behaviors among college students. Curr Addict Rep. (2016) 3:35667. doi: 10.1007/s40429-016-0126-7

23. Census and Statistics Department. Thematic Household Survey Report - Report No. 61- Use of new media [Internet]. Available online at: https://www.statistics. gov.hk/pub/B11302612016XXXXB0100.pdf (cited April 16, 2020)

24. Leung L. Linking psychological attributes to addiction and improper use of the mobile phone among adolescents in Hong Kong. J Child Media. (2008) 2:93-113. doi: 10.1080/17482790802078565

25. Yu L, Shek DTL. Testing longitudinal relationships between Internet addiction and well-being in Hong Kong adolescents: cross-lagged analyses based on three waves of data. Child Indic Res. (2018) 11:1545-62. doi: 10.1007/s12187-017-9494-3

26. Wang CW, Ho RTH, Chan CLW, Tse S. Exploring personality characteristics of Chinese adolescents with internet-related addictive behaviors: trait differences for gaming addiction and social networking addiction. Addict Behav. (2015) 42:32-5. doi: 10.1016/j.addbeh.2014.10.039

27. Griffiths MD, Kuss DJ, Demetrovics Z. Social networking addiction: An overview of preliminary findings. In Rosenberg KP, Curtiss Feder L, editors, Behavioral Addictions: Criteria, Evidence, and Treatment (p. 119-141). Cambridge, MA: Elsevier Academic Press (2014). doi: 10.1016/B978-0-12-407724-9.00006

28. Monacis, L., Griffiths, M.D., Limone, P., Sinatra, M., Servidio, R. Selfitis behavior: assessing the italian version of the selfitis behavior scale and its mediating role in the relationship of dark traits with social media addiction. Int J Environ Res Publ Health. (2020) 17:5738. doi: 10.3390/ijerph171 65738

29. Ko CH, Wang PW, Liu TL, Yen CF, Chen CS, Yen JY. Bidirectional associations between family factors and Internet addiction among adolescents in a prospective investigation. Psychiatry Clin Neurosci. (2015) 69:192200. doi: 10.1111/pcn.12204

30. Lee SJ, Chae YG. Children's Internet use in a family context: influence on family relationships and parental mediation. Cyberpsychol Behav. (2007) 10:640-4. doi: 10.1089/cpb.2007.9975

31. Yen JY, Yen CF, Chen CC, Chen SH, Ko CH. Family factors of internet addiction and substance use experience in Taiwanese adolescents. Cyberpsychol Behav. (2007) 10:323-9. doi: 10.1089/cpb.2006.9948

32. Tur-Porcar A. Parenting styles and Internet use. Psychol Mark. (2017) 34:1016-22. doi: 10.1002/mar.21040

33. Wu CST, Wong HT, Yu KF, Fok KW, Yeung SM, Lam CH, et al. Parenting approaches, family functionality, and internet addiction among Hong Kong adolescents. BMC Pediatr. (2016) 16:130. doi: 10.1186/s12887-016-0666-y

34. Barber B K. Intrusive Parenting: How Psychological Control Affects Children and Adolescents. 1st Edn. American Psychological Association (2002).

35. Siomos K, Floros G, Fisoun V, Evaggelia D, Farkonas N, Sergentani E, et al. Evolution of Internet addiction in Greek adolescent students over a two-year period: the impact of parental bonding. Eur Child Adolesc Psychiatry. (2012) 21:211-9. doi: 10.1007/s00787-012-0254-0

36. Lin $\mathrm{CH}$, Lin SL, Wu CP. The effects of parental monitoring and leisure boredom on adolescents' Internet addiction. Adolescence. (2009) 44:993-1004. doi: 10.3390/ijerph17051754

37. Ding Q, Li D, Zhou Y, Dong H, Luo J. Perceived parental monitoring and adolescent internet addiction: A moderated mediation model. Addict Behav. (2017) 74:48-54. doi: 10.1016/j.addbeh.2017.05.033

38. Wills TA, Resko JA, Ainette MG, Mendoza D. Role of parent support and peer support in adolescent substance use: a test of mediated effects. Psychol Addict Behav. (2004) 18:122-34. doi: 10.1037/0893-164X.18.2.122

39. van Den Eijnden RJJM, Spijkerman R, Vermulst AA, van Rooij TJ, Engels RC. Compulsive Internet use among adolescents: Bidirectional parent-child relationships. J Abnorm Child Psychol. (2010) 38:77-89. doi: 10.1007/s10802-009-9347-8

40. Park SK, Kim JY, Cho CB. Prevalence of Internet addiction and correlations with family factors among South Korean adolescents. Adolescence. (2008) 43:895-909.

41. Chng GS, Li D, Liau AK, Khoo A. Moderating effects of the family environment for parental mediation and pathological internet use in youths. Cyberpsychol Behav Soc Netw. (2015) 18:30-6. doi: 10.1089/cyber.2014.0368 
42. Grotevant HD. Adolescent development in family contexts. In Damon W, Eisenberg N, editors. Handbook of Child Psychology: Social, Emotional, and Personality Development. New Jersey, NJ: John Wiley \& Sons, Inc. (1998). p. 1097-149.

43. Goldenberg I, Goldenberg H. Family Therapy: An Overview. 5th Edn. Belmont, WA: Wadsworth Publishing Company (2005).

44. Abar C, Turrisi R. How important are parents during the college years? A longitudinal perspective of indirect influences parents yield on their college teens' alcohol use. Addict Behav. (2008) 33:13608. doi: 10.1016/j.addbeh.2008.06.010

45. Kaynak Ö, Meyers K, Caldeira KM, Vincent KB, Winters KC, Arria AM. Relationships among parental monitoring and sensation seeking on the development of substance use disorder among college students. Addict Behav. (2013) 38:1457-63. doi: 10.1016/j.addbeh.2012.08.003

46. Mallett KA, Turrisi R, Ray AE, Stapleton J, Abar C, Mastroleo NR, et al. Do parents know best? Examining the relationship between parenting profiles, prevention efforts, and peak drinking in college students 1. J Appl Soc Psychol. (2011) 41:2904-27. doi: 10.1111/j.1559-1816.2011.00860.x

47. Small ML, Morgan N, Abar C, Maggs JL. Protective effects of parent-college student communication during the first semester of college. J Am Coll Health. (2011) 59:547-54. doi: 10.1080/07448481.2010.528099

48. Fischer JL, Forthun LF, Pidcock BW, Dowd DA. Parent relationships, emotion regulation, psychosocial maturity and college student alcohol use problems. $J$ Youth Adolesc. (2007) 36:912-26. doi: 10.1007/s10964-006-9126-6

49. Yao MZ, He J, Ko DM, Pang K. The influence of personality, parental behaviors, and self-esteem on Internet addiction: a study of Chinese college students. Cyberpsychol Behav Soc Netw. (2014) 17:104-10. doi: 10.1089/cyber.2012.0710

50. Hong Kong Professional Teachers' Union [Internet]. Available online at: https://www.hkptu.org/ptunews/42592 (cited April 16, 2020).

51. Su C, Hynie M. Effects of life stress, social support, and cultural norms on parenting styles among mainland Chinese, European Canadian, and Chinese Canadian immigrant mothers. J Cross Cult Psychol. (2011) 42:94462. doi: 10.1177/0022022110381124

52. Chao RK. Chinese and European American cultural models of the self reflected in mothers' childrearing beliefs. Ethos. (1995) 23:328-54.

53. Lim S L, Lim B K. Parenting style and child outcomes in Chinese and immigrant Chinese families-current findings and cross-cultural considerations in conceptualization and research. Marriage Fam Rev. (2004) 35:21-43. doi: 10.1300/J002v35n03_03

54. Pomerantz EM, Wang Q. The role of parental control in children's development in Western and East Asian countries. Curr Dir Psychol Sci. (2009) 18:285-9. doi: 10.1111/j.1467-8721.2009.01653.x

55. Shek DTL. Paternal and maternal influences on family functioning among Hong Kong Chinese families. J Genet Psychol. (2001) 162:5674. doi: 10.1080/00221320109597881

56. Livingstone S, Helsper EJ. Parental mediation of children's internet use. J Broadcast Electron Media. (2008) 52:58199. doi: 10.1080/08838150802437396

57. Koning IM, Peeters M, Finkenauer C, Van Den Eijnden RJ. Bidirectional effects of Internet-specific parenting practices and compulsive social media and Internet game use. J Behav Addict. (2018) 7:624-32. doi: 10.1556/2006.7.2018.68

58. Van Den Eijnden RJJM, Lemmens JS, Valkenburg PM. The social media disorder scale. Comput Human Behav. (2016) 61:478-87. doi: 10.1016/j.chb.2016.03.038

59. Fung S. Cross-cultural validation of the Social Media Disorder scale. Psychol Res Behav Manage. (2019) 12:683-90. doi: 10.2147/PRBM.S216788

60. Savci M, Ercengiz M, Aysan F. Turkish adaptation of the Social Media Disorder Scale in adolescents. Noro Psikiyatr Ars. (2018) 55:24855. doi: 10.5152/npa.2017.19285

61. Diener E. Subjective well-being. Psychol Bull. (1984) 95:542-75.

62. Chen W, Zhang D, Pan Y, Hu T, Liu G, Luo S. Perceived social support and self-esteem as mediators of the relationship between parental attachment and life satisfaction among Chinese adolescents. Pers Individ Dif. (2017) 108: 98-102. doi: 10.1016/j.paid.2016.12.009

63. de Looze ME, Huijts T, Stevens G, Torsheim T, Vollebergh WA. The happiest kids on earth. Gender equality and adolescent life satisfaction in Europe and North America. J Youth Adolesc. (2018) 47:107385. doi: 10.1007/s10964-017-0756-7

64. Kroenke K, Spitzer RL, Williams JB. The phq-9. J Gen Intern Med. (2001) 16:606-13. doi: 10.1046/j.1525-1497.2001.016009606.x

65. Pinto-Meza A, Serrano-Blanco A, Penarrubia MT, Blanco E, Haro JM. Assessing depression in primary care with the PHQ-9: can it be carried out over the telephone? J Gen Intern Med. (2005) 20:73842. doi: 10.1111/j.1525-1497.2005.0144.x

66. Tsai FJ, Huang YH, Liu HC, Huang KY, Huang YH, Liu SI. Patient health questionnaire for school-based depression screening among Chinese adolescents. Pediatrics. (2014) 133:e402-9. doi: 10.1542/peds.201 3-0204

67. Buysse DJ, Reynolds CF, Monk TH, Berman, SR, Kupfer DJ. The Pittsburgh Sleep Quality Index: a new instrument for psychiatric practice and research. Psychiatry Res. (1989) 28:193-213.

68. Dietch JR, Taylor DJ, Sethi K, Kelly K, Bramoweth AD, Roane BM. Psychometric evaluation of the PSQI in US college students. J Clin Sleep Med. (2016) 12:1121-9. doi: 10.5664/jcsm.6050

69. Guo S, Sun W, Liu C, Wu S. Structural validity of the Pittsburgh sleep quality index in Chinese undergraduate students. Front Psychol. (2016) 7:112632. doi: $10.3389 /$ fpsyg.2016.01126

70. Wan C. Gratifications \& Loneliness as Predictors of Campus-SNS. Hong Kong: The Chinese University of Hong Kong (2009). Available online at: http://pg. com.cuhk.edu.hk/pgp_nm/projects/2009/Wan\%20Sisi\%20Candy.pdf

71. Lenhart A. Teens, Social Media \& Technology Overview [Internet]. Available online at: https://www.pewresearch.org/internet/2015/04/09/teenssocial-media-technology-2015/ (cited April 16, 2020).

72. Muscanell NL, Guadagno RE. Make new friends or keep the old: gender and personality differences in social networking use. Comput Human Behav. (2012) 28:107-12. doi: 10.1016/j.chb.2011.08.016

73. Hwang HS, Choi EK. Exploring gender differences in motivations for using Sina Weibo. KSII Trans Intern Inform Syst. (2016) 10:142941. doi: $10.3837 /$ tiis.2016.03.029

74. Griffiths MD. Online computer gaming: advice for parents and teachers. Educ Health. (2009) 27:3-6.

75. Lepp A, Barkley JE, Karpinski AC. The relationship between cell phone use, academic performance, anxiety, and satisfaction with life in college students. Comput Human Behav. (2014) 31:343-50. doi: 10.1016/j.chb.2013. 10.049

76. Utz S, Breuer J. The relationship between use of social network sites, online social support, and well-being: Results from a six-wave longitudinal study. J Media Psychol. (2017) 29:115-25. doi: 10.1027/1864-1105/a0 00222

77. Woods HC, Scott H. Sleepyteens: social media use in adolescence is associated with poor sleep quality, anxiety, depression and low self-esteem. J Adolesc. (2016) 51:41-9. doi: 10.1016/j.adolescence.2016.05.008

78. Ho H, Shin W, Lwin MO. Social networking site use and materialistic values among youth: the safeguarding role of the parent-child relationship and self-regulation. Commun Res. (2019) 46:1119-44. doi: 10.1177/00936502166 83775

79. Martins MV, Formiga A, Santos C, Sousa D, Resenda C, Campos $\mathrm{R}$, et al. Adolescent internet addiction-role of parental control and adolescent behaviours. Int J Pediatr Adolesc Med. (2019) 7:116-20. doi: 10.1016/j.ijpam.2019.12.003

80. Hsieh YP, Shen ACT, Wei HS, et al. Internet addiction: a closer look at multidimensional parenting practices and child mental health. Cyberpsychol Behav Soc Netw. (2018) 21:768-73. doi: 10.1089/cyber.201 8.0435

81. Chang FC, Chiu CH, Miao NF, Chen PH, Lee CM, Chiang JT, et al. The relationship between parental mediation and Internet addiction among adolescents, and the association with cyberbullying and depression. Comprehens Psychiatry. (2015) 57:21-8. doi: 10.1016/j.comppsych.2014.11.013

82. Lee SJ. Parental restrictive mediation of children's internet use: effective for what and for whom? New Media Soc. (2013) 15:466-81. doi: 10.1177/1461444812452412

83. Chou C, Lee YH. The moderating effects of Internet parenting styles on the relationship between Internet parenting behavior, Internet expectancy, 
and Internet addiction tendency. Asia-Pac Educ Res. (2017) 26:13746. doi: 10.1007/s40299-017-0334-5

84. Zhang R, Bai B, Jiang S, Yang S, Zhou Q. Parenting styles and internet addiction in Chinese adolescents: conscientiousness as a mediator and teacher support as a moderator. Comput Hum Behav. (2019) 101:144-50. doi: 10.1016/j.chb.2019.07.019

85. Brody GH, Flor DL, Hollett-Wright N, McCoy JK, Donovan J. Parentchild relationships, child temperament profiles and children's alcohol use norms. J Stud Alcohol Suppl. (1999) (13):45-51. doi: 10.15288/jsas.1999. s13.45

86. DeBoard-Lucas RL, Fosco GM, Raynor SR, Grych JH. Interparental conflict in context: exploring relations between parenting processes and children's conflict appraisals. $J$ Clin Child Adolesc Psychol. (2010) 39:163-75. doi: 10.1080/153744109035 32593

87. Brechwald WA, Prinstein MJ. Beyond homophily: a decade of advances in understanding peer influence processes. $J$ Res Adolesc. (2011) 21:166-79. doi: 10.1111/j.1532-7795.2010.0 0721.x

88. Meeus WIM, Oosterwegel A, Vollebergh W. Parental and peer attachment and identity development in adolescence. J Adolesc. (2002) 25:93106. doi: 10.1006/jado.2001.0451

89. Gunuc S. Peer Influence in Internet and Digital Game Addicted Adolescents: Is Internet/Digital Game Addiction Contagious?. Int J High Risk Behav Addict. (2017) 6(2). doi: 10.5812/ijhrba.33681
90. Larimer ME, Turner AP, Mallett KA, Geisner IM. Predicting drinking behavior and alcohol-related problems among fraternity and sorority members: examining the role of descriptive and injunctive norms. Psychol of Addict Behav. (2004) 18:203-12. doi: 10.1037/0893-164X.1 8.3.203

91. The Hong Kong and Shanghai Banking Corporation Limited. University Students in Hong Kong Take Up Part-Time Jobs to Keep With Costs and Enhance Job Prospects [Internet]. Available online at: https://www.about.hsbc. com.hk/-/media/hong-kong/en/news-and-media/180821-over-nine-in-tenuniversity-students-in-hong-kong-take-up-part-time-jobs.pdf (cited April $16,2020)$.

92. Lemmens J S, Valkenburg P M, Peter J. Psychosocial causes and consequences of pathological gaming. Comput Human Behav. (2011) 27:14452. doi: 10.1016/j.chb.2010.07.015

Conflict of Interest: The authors declare that the research was conducted in the absence of any commercial or financial relationships that could be construed as a potential conflict of interest.

Copyright (C) $2021 \mathrm{Yu}$ and Luo. This is an open-access article distributed under the terms of the Creative Commons Attribution License (CC BY). The use, distribution or reproduction in other forums is permitted, provided the original author(s) and the copyright owner(s) are credited and that the original publication in this journal is cited, in accordance with accepted academic practice. No use, distribution or reproduction is permitted which does not comply with these terms. 